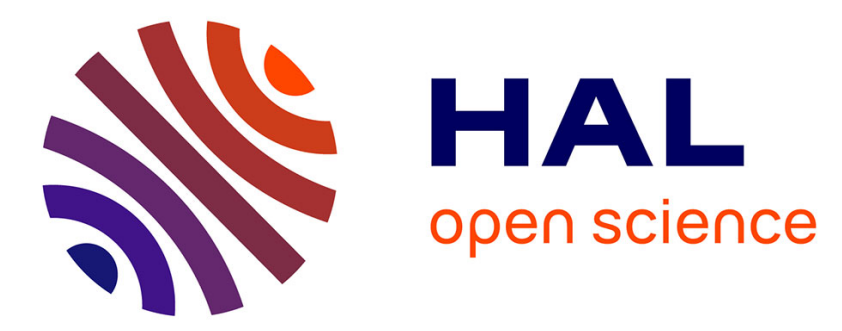

\title{
Sociocognitive Self-Regulatory Mechanisms Governing Judgments of the Acceptability and Likelihood of Sport Cheating
}

Fabienne d'Arripe-Longueville, Karine Corrion, Stéphanie Scoffier-Mériaux, Peggy Roussel, Aïna Chalabaev

\section{To cite this version:}

Fabienne d'Arripe-Longueville, Karine Corrion, Stéphanie Scoffier-Mériaux, Peggy Roussel, Aïna Chalabaev. Sociocognitive Self-Regulatory Mechanisms Governing Judgments of the Acceptability and Likelihood of Sport Cheating. Journal of Sport and Exercise Psychology, 2010, 32, pp.595 - 618. 10.1123/jsep.32.5.595 . hal-02524745

\section{HAL Id: hal-02524745 \\ https://hal.univ-cotedazur.fr/hal-02524745}

Submitted on 6 Apr 2020

HAL is a multi-disciplinary open access archive for the deposit and dissemination of scientific research documents, whether they are published or not. The documents may come from teaching and research institutions in France or abroad, or from public or private research centers.
L'archive ouverte pluridisciplinaire HAL, est destinée au dépôt et à la diffusion de documents scientifiques de niveau recherche, publiés ou non, émanant des établissements d'enseignement et de recherche français ou étrangers, des laboratoires publics ou privés. 


\title{
Sociocognitive Self-Regulatory Mechanisms Governing Judgments of the Acceptability and Likelihood of Sport Cheating
}

\author{
Fabienne d'Arripe-Longueville, ${ }^{1}$ Karine Corrion, ${ }^{1}$ \\ Stéphanie Scoffier, ${ }^{1}$ Peggy Roussel, ${ }^{2}$ and Aïna Chalabaev ${ }^{1}$ \\ ${ }^{1}$ University of Nice Sophia-Antipolis; ${ }^{2}$ Rennes II University
}

\begin{abstract}
This study extends previous psychosocial literature (Bandura et al., 2001, 2003) by examining a structural model of the self-regulatory mechanisms governing the acceptability and likelihood of cheating in a sport context. Male and female adolescents $(N=804)$, aged $15-20$ years, took part in this study. Negative affective self-regulatory efficacy influenced the acceptability and likelihood of cheating through the mediating role of moral disengagement, in females and males. Affective efficacy positively influenced prosocial behavior through moral disengagement or through resistive self-regulatory efficacy and social efficacy, in both groups. The direct effects of affective efficacy on beliefs about cheating were only evident in females. These results extend the findings of Bandura et al. (2001, 2003 ) to the sport context and suggest that affective and resistive self-regulatory efficacy operate in concert in governing adolescents' moral disengagement and transgressive behaviors in sport.
\end{abstract}

Keywords: self-regulatory efficacy, moral development, transgressive behavior, adolescence, sport, gender

Sport is generally used as a means to develop moral values such as loyalty, fairness, and cooperation, although antisocial behaviors have often been reported in this domain (e.g., Shields, Bredemeier, LaVoi, \& Power, 2005; Weinstein, Smith, \& Wiesenthal, 1995). This contradiction has prompted sport psychologists to expand research on morality in sport (e.g., Kavussanu, 2006; Lee, Whitehead, Ntoumanis, \& Hatzigeorgiadis, 2008; see Weiss, Smith, \& Stuntz, 2008, for a review). Bandura's (1991) social cognitive theory has been widely used to examine moral

Fabienne d'Arripe-Longueville is with the Laboratoire Motricité Humaine, Education, Santé, University of Nice Sophia-Antipolis, France. Karine Corrion is with the Laboratoire Motricité Humaine, Education, Santé, University of Nice Sophia-Antipolis, France. Stéphanie Scoffier is with the Laboratoire Motricité Humaine, Education, Santé, University of Nice Sophia-Antipolis, France. Peggy Roussel is with Rennes II University, France. Aïna Chalabaev is with the Laboratoire Motricité Humaine, Education, Santé, University of Nice Sophia-Antipolis, France. 
thought and action in adolescents (e.g., Bandura, Caprara, Barbaranelli, Gerbino, \& Pastorelli, 2003; Bandura, Caprara, Barbaranelli, Pastorelli, \& Regalia, 2001; Caprara et al., 1998). To our knowledge, however, no study to date has specifically used this framework to explore the self-regulatory mechanisms of morality in sport contexts. This was the aim of the current study.

According to social cognitive theory, the capacity for self-regulation is one of the core features of human agency (Bandura, 1991, 1999). Self-regulation requires self-monitoring or observation of one's actions, self-judgment of behavior in relation to personal standards and environmental circumstances, and affective self-reaction. The self-regulatory mechanisms through which moral agency are exercised are of special relevance to the self-management of transgressive behavior (Bandura et al., 2001, 2003). From the perspective of social cognitive theory (Bandura, 1999), moral agency has dual aspects: inhibitive and proactive. The inhibitive form of morality is expressed by the power to refrain from behaving inhumanely (e.g., refraining from deliberately trying to injure an opponent). The proactive form of morality is expressed by the power to behave humanely (e.g., congratulating an opponent on good play). Once the individual has set personal standards, both negative self-sanctions for actions that violate moral standards and positive self-reactions for conduct that meets the standards serve as regulatory influences (Bandura, 1991). These self-reactive influences are both motivational and cognitive regulators of moral conduct (Bandura et al., 2001). In past sport psychology research (e.g., Boardley \& Kavussanu, 2009a; Kavussanu, Seal, \& Phillips, 2006; Sage, Kavussanu, \& Duda, 2006), the terms prosocial and antisocial behavior were respectively used to refer to the proactive and inhibitive aspects of morality. Prosocial behavior refers to actions intended to benefit a person other than oneself (Eisenberg \& Fabes, 1998), whereas antisocial behavior refers to actions intended to harm or disadvantage another, such as cheating (Kavussanu, 2006).

Among the sociocognitive self-regulatory mechanisms governing transgressive behavior, self-efficacy beliefs play a pivotal role because they affect actions both directly and through their impact on cognitive, motivational, decisional, and affective determinants (e.g., Bandura et al., 2001, 2003). Although perceived selfefficacy serves a regulatory function in all developmental periods, it is especially important during adolescence, which is often a time of exploratory engagement in high-risk activities, such as substance abuse, unprotected sex, and transgressive conduct in various domains, including sports (Leffert \& Petersen, 1995). Recent research has shown that different facets of perceived self-efficacy, such as academic efficacy and social efficacy (Bandura, Pastorelli, Barbaranelli, \& Caprara, 1999), resistive self-regulatory efficacy (Bandura et al., 2001), and affective self-regulatory efficacy (Bandura et al., 2003), should be taken into account to understand transgressive behavior in adolescents. In the current study, we examined three types of efficacy: resistive self-regulatory efficacy, social efficacy, and affective self-regulatory efficacy.

Self-regulatory efficacy to resist temptation or pressure to behave transgressively refers to the belief in one's capabilities to achieve personal control of behavior (Bandura et al., 2001, 2003; Caprara et al., 1998). It is important because negative peer modeling and peer pressure may increase developmental risks by promoting antisocial conduct in everyday life (Bandura et al., 2001, 2003; Caprara et al., 1998) and in physical activity contexts (e.g., Stuntz \& Weiss, 2003). Both 
cross-sectional and longitudinal designs indicate that the belief in one's efficacy to resist peer pressure reduces the likelihood of antisocial conduct. For instance, Caprara and colleagues (1998) found that adolescents who reported a high sense of efficacy to resist peer pressure also reported open communication with parents about activities outside the home and low engagement in delinquent conduct and substance abuse. Bandura and colleagues demonstrated that resistive self-regulatory efficacy influenced adolescents' transgressive behaviors (e.g., physical and verbal aggression, theft, cheating, lying), both directly (Bandura et al., 2001, 2003) and indirectly through prosocial behavior and adherence to moral self-sanctions for harmful conduct (Bandura et al., 2001). Caprara, Regalia, and Bandura (2002) first controlled for prior levels of transgressive behavior and the quality of familial relationships and found that self-regulatory inefficacy predicted transgressive behavior.

Perceived social self-efficacy is another important predictor of prosocial and antisocial behaviors (Bandura et al., 2001). Social efficacy measures individuals' beliefs in their capabilities to form and maintain social relationships, work cooperatively with others, and manage different types of interpersonal conflicts (Bandura et al., 2001). These authors showed that the impact of social efficacy to abstain from transgressive behavior was mediated through the enhancement of prosocial behavior. Furthermore, Caprara and Steca (2005) reported that social efficacy positively influenced adults' life satisfaction through prosocial behavior.

Bandura et al. (2003) identified another type of central self-regulatory efficacy related to affectivity, which has been shown to influence attentional, cognitive, and motivational processes (Gross \& Munoz, 1995; Larsen, 2000). Affect is often the basis for social ties and their durability, thereby influencing the course of lives (Bandura, 1986). Bandura et al. (2003) explored how perceived self-efficacy for affect regulation operates in concert with perceived behavioral efficacy in governing diverse spheres of psychological functioning. These authors extended the role of affective self-regulatory efficacy in the management of the transitional stressors of adolescence. They showed that self-efficacy to regulate positive and negative affect was related to high efficacy to manage one's academic development and to resist social pressures for antisocial activities. In addition, efficacy to regulate negative affect impacted antisocial behavior directly. These findings were supported and extended by Caprara and Steca (2005), who reported that a strong sense of efficacy in the regulation of negative affect was associated with life satisfaction both directly and through social self-efficacy and prosocial behavior. Recently, Gano-Overway et al. (2009) examined the mediating roles of positive and negative affective self-regulatory efficacy and of empathic efficacy in the relationship between caring sport contexts and social behaviors. They observed that perceptions of a caring climate positively predicted positive affective efficacy, which in turn positively predicted empathic efficacy. Prosocial behavior was positively linked to empathic efficacy, whereas antisocial behavior was negatively predicted by positive affective efficacy. Together these recent studies show that affective self-regulatory efficacy is a significant variable to consider when studying prosocial and antisocial behaviors in youth.

Moral disengagement is another mediating variable that is important to understanding transgressive behavior in adolescents. Moral disengagement appears when moral self-sanctions are selectively disengaged from detrimental conduct. It is a self-regulatory process by which individuals cognitively restructure their inhumane 
conduct, their role in causing harm, the negative effects of their actions, or the targets of their transgressive acts (Bandura 1991, 1999; Bandura et al. 2001). For Bandura (1999), moral disengagement is characterized by eight mechanisms (i.e., moral justification; advantageous comparison; euphemistic labeling; minimizing, distorting, or ignoring consequences; attribution of blame; dehumanization; displacement of responsibility; and diffusion of responsibility) that allow individuals to transgress without experiencing negative affect. These moral disengagement mechanisms have been shown to be related to the reasons given by competitive athletes for transgressing sport rules (Corrion, Long, Smith, \& d'Arripe-Longueville, 2009b; Long, Pantaleon, Bruant, \& d'Arripe-Longueville, 2006). Several factors have also been examined in relation to moral disengagement in sport including age, gender, and sport type (Boardley \& Kavussanu, 2007). Recent research has identified links between moral disengagement and prosocial and antisocial behavior in team sport. Moral disengagement has been found to be positively related to antisocial behaviors, and negatively related to prosocial behaviors (Boardley \& Kavussanu, 2007, 2009a, 2009b). Boardley and Kavussanu (2009a) recently reported that moral disengagement had a mediational role in the positive relationship between perceived character-building competency and prosocial behavior toward opponents, and in the negative relationship between perceived character-building competency and antisocial behaviors, in team-sports players. Moreover, Lucidi and colleagues showed that moral disengagement was a positive predictor of both the intention to use doping substances (Lucidi, Grano, Leone, Lombardo, \& Pesce, 2004) and the actual use of these substances (Lucidi et al., 2008). Basing their study on the theory of planned behavior (Ajzen, 1991), these authors showed that doping attitudes, beliefs that significant others would approve of doping, and the conviction that doping use can be justified positively predicted the intention to use doping substances, whereas the capacity to resist situational pressure or personal desires negatively predicted this intention. In turn, intentions and moral disengagement positively predicted the use of doping substances.

The results of Lucidi and colleagues (2008) provide novel information about some of the psychological processes regulating adolescents' use of doping substances and supplements. However, doping is extremely transgressive behavior. It is unknown whether their findings would be replicated for more common transgressive behaviors such as cheating (e.g., a student in a physical education class pulling his/her opponent's jersey during a match to prevent him/her from scoring a goal). Moreover, although Lucidi et al. (2008) considered self-regulatory efficacy as a key social cognitive construct in understanding transgressive behavior, this construct was not examined within the framework of social cognitive theory from Bandura et al. (2001, 2003). Gano-Overway et al. (2009) studied the determinants of moral behavior in sport within this framework, but only self-regulatory efficacy related to affectivity was investigated. Thus, investigating the self-regulatory processes through which moral agency is exercised within the theoretical framework provided by Bandura et al. (2001, 2003) could enrich our understanding of the factors that predict unsportspersonlike cognitions, affective responses, and behaviors.

The present study, therefore, replicated and extended the models of Bandura et al. $(2001,2003)$ to study beliefs about cheating in sport (i.e., cheating acceptability and intention to cheat). The model we tested included the main relationships in the model of Bandura et al. (2001), which enabled us to examine the impact 
of resistive self-regulatory efficacy and social self-efficacy on prosocial behavior and beliefs about cheating through the influence of moral disengagement. These variables were selected on the basis of recent results in the sport psychology literature suggesting the role of self-regulatory mechanisms in moral functioning in sport (d'Arripe-Longueville, Weiss, Pantaleon, \& Raimbault, 2005; Boardley \& Kavussanu, 2009a; Gano-Overway et al., 2009). Academic self-efficacy was not included in the model because it was not deemed relevant to the sport domain. Although recent research has reported that both positive and negative affective self-regulatory efficacy might influence prosocial and antisocial behavior, the current study focused on self-efficacy to regulate negative affect which was found to impact antisocial behavior (Bandura et al., 2003) and life satisfaction (Caprara \& Steca, 2005) directly. Yet in the context of youth sport, no significant relationship emerged between negative affective self-regulatory efficacy and antisocial conduct (Gano-Overway et al., 2009). These discrepant findings prompted us to investigate this relationship further. We thus examined the structural paths of influence through which perceived self-efficacy for negative affect regulation operates in concert with resistive self-regulatory efficacy and social self-efficacy (Bandura et al., 2003) in governing beliefs about cheating. The simultaneous consideration of negative affective efficacy, resistive self-regulatory efficacy, and social efficacy to explain moral variables is thus unique to the current study and particularly appropriate to the sport context.

Gender differences in moral functioning have been reported in the literature from both social psychology (Bandura et al., 2001, 2003) and sport psychology (e.g., Bredemeier \& Shields, 1986; Stuntz \& Weiss, 2003). Bandura et al. (2001) showed that boys expressed lower resistive self-regulatory efficacy than girls and were less prosocial, more prone to disengage moral self-sanctions for harmful conduct, and more likely to engage in transgressive activities. In addition, males were found to report higher perceived capability of regulating their negative affects (Bandura et al., 2003; Caprara \& Steca, 2005). Sport psychology research has also shown that males generally report lower moral functioning and express more unsportspersonlike behavior than females. For example, Bredemeier and Shields (1986) found that female high school basketball players displayed more mature moral reasoning than their male counterparts in response to both life and sport dilemmas. Moreover, studies have consistently shown that males perceive injurious and aggressive behavior as more legitimate than females do in both contact and noncontact sports (e.g., Bredemeier, 1985; Gardner \& Janelle, 2002; Miller, Roberts, $\&$ Ommundsen, 2005). Given these gender differences, gender was considered in the viability testing of the proposed model.

Based on the findings of Bandura et al. (2001), it was expected that resistive self-regulatory efficacy would be (a) negatively related to judgment of the acceptability and likelihood of cheating both directly and indirectly through moral disengagement and (b) positively related to prosocial behavior by fostering social self-efficacy (see Figure 1). Based on more recent results from Bandura et al. (2003), it was hypothesized that negative affective self-regulatory efficacy would negatively impact beliefs about cheating both directly and indirectly through resistive self-efficacy. Gano-Overway et al. (2009) found no significant relationship between negative affective self-regulatory efficacy and antisocial behavior; however, given the absence of a theoretical explanation of these results, our hypotheses 
were based on the results from Bandura et al. (2003). In addition, social efficacy was expected to play a mediational role between negative affective efficacy and prosocial behavior (Caprara \& Steca, 2005). Our structural model also tested some specific functional relationships between efficacy beliefs and cheating variables that were not considered in the models from Bandura et al. $(2001,2003)$ but that were deemed appropriate to the sport context. First, we expected that moral disengagement would mediate the relationships between (a) negative affective efficacy and prosocial behavior, and (b) negative affective efficacy and beliefs about cheating. Indeed, affective efficacy was found to predict resistive efficacy (Bandura et al., 2003) and moral disengagement was found to play a mediational role between (a) resistive efficacy and prosocial behavior and (b) resistive efficacy and transgressive behavior (Bandura et al., 2001). Second, social efficacy was also expected to play a mediational role between negative affective efficacy and moral disengagement (Caprara \& Steca, 2005). Male adolescents were expected to report greater capabilities to regulate negative affect, higher moral disengagement, and more unfavorable beliefs about the acceptability and likelihood of sport cheating than female adolescents, whereas females were expected to report higher resistive selfregulatory efficacy and prosocial behavior (Bandura et al., 2001, 2003).

\section{Method}

\section{Participants}

Eight hundred and four older French adolescents (380 males and 424 females) voluntarily participated in the study, which was conducted in a school district of Nice, France. All parents first provided informed written consent and the study was conducted in compliance with APA ethical standards. The average age of the participants was 17.2 years with a range of $15-20$ years $(S D=1.16)$. The participants were predominantly from middle-class Caucasian areas.

\section{Measures}

Resistive Self-Regulatory Efficacy. Resistive self-regulatory efficacy was assessed using a French validated version of the Self-Regulatory Scale by Bandura, Barbaranelli, Caprara and Pastorelli (1996), which has been adapted to the sport context (Corrion, Gernigon, Garbarino, Cury, \& d'Arripe-Longueville, 2009a). The original scale assesses children's self-regulatory efficacy to resist engaging in high-risk activities like alcohol, drug use, and transgressive behaviors that could get them into trouble. The sport resistive self-regulatory scale consists of six items scored on a Likert scale from not at all capable (1) to totally capable (7). For instance, one item of the Bandura et al. scale is "How well can you resist peer pressure to drink beer, wine, or liquor?" This item was adapted to the sport context and changed to "How well can you resist peer pressure to cheat in sport?" Another item is "How well can you resist peer pressure to do things in school that can get you into trouble?" and it was changed to "How well can you resist peer pressure to do things in your sport that can get you into trouble?"

This scale was previously developed and validated using a sample of 796 independent adolescents (Corrion et al., 2009a) and the protocol outlined by 


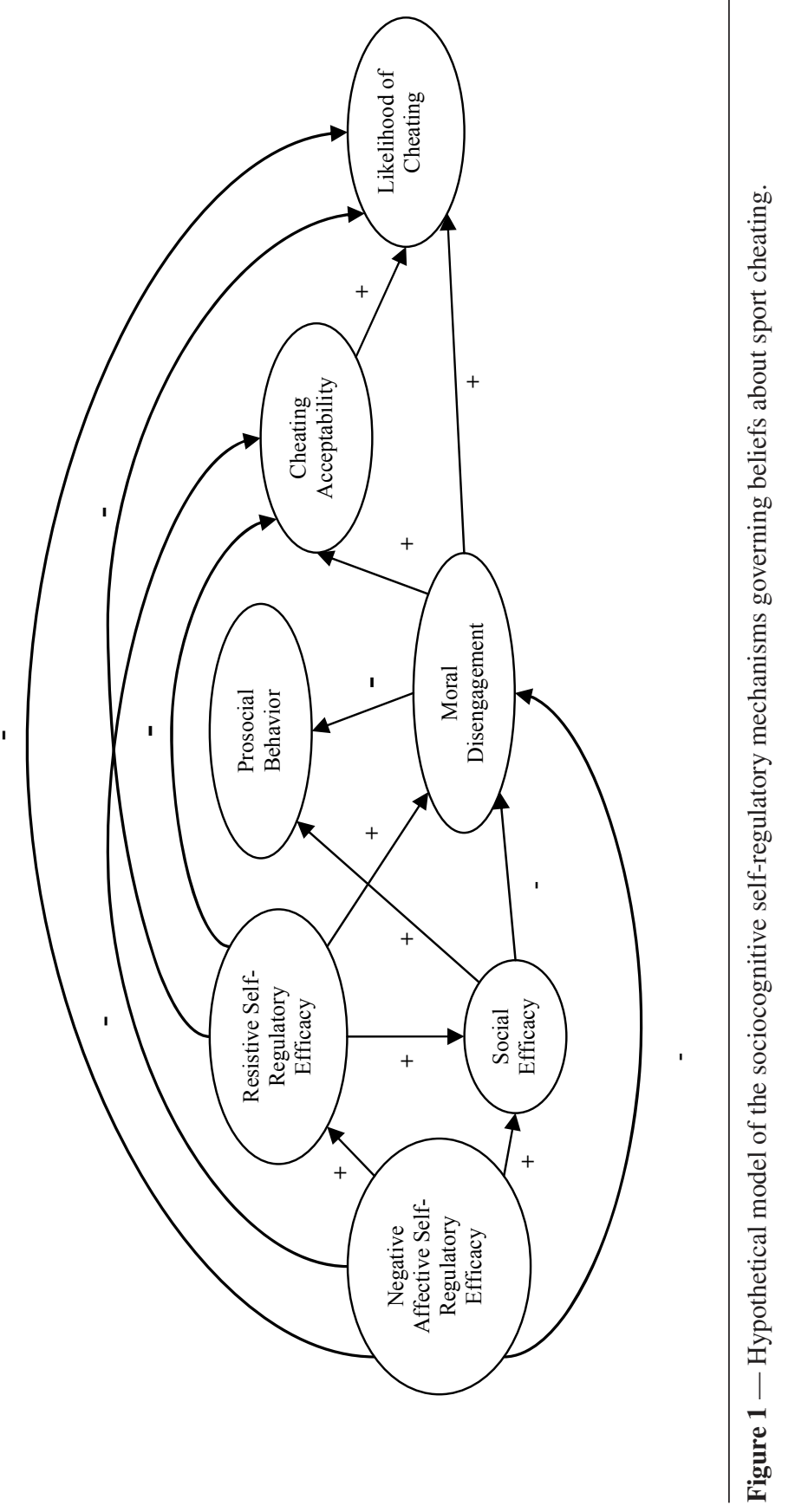


Vallerand (1989). First, the items were completely translated into French by two bilingual sport psychology researchers. This resulted in an eight-item preliminary version. To assess the clarity of the items for the target population, 20 adolescents (i.e., 10 boys, 10 girls) completed the questionnaire and explained how they interpreted the meaning of each of the items during an interview. This resulted in minor changes in two items. The factorial validity of the scale was tested using a series of Confirmatory Factorial Analyses (CFA), and bootstrap resampling was performed with AMOS 7.0 software (Arbuckle, 2006). An initial factorial analysis with 270 participants suggested the elimination of two items; subsequent analyses with 526 other students revealed that the six-item model including a path from Item 5 to Item 6 was significantly adjusted to the data, that is, $\chi^{2}(8)=26.76 ; N=$ 526 ; $\mathrm{CFI}=.99 ; \mathrm{TLI}=.98 ; \mathrm{RMSEA}=.067$; Confidence Interval $(\mathrm{CI})$ for RMSEA $=.040 / .096$. In the current study, the original six-item model (including a path from Item 5 to Item 6 ) provided a good fit, $\chi^{2}(8)=14.72 ; N=804 ;$ CFI $=.99$; TLI $=.99 ;$ RMSEA $=.032 ;$ CI RMSEA $=.000 / .058$. The internal consistency of the scale was satisfactory $(\alpha=.92)$.

Negative Affective Self-Regulatory Efficacy. Affective self-regulatory efficacy was assessed using a four-item subscale of the French version of the Social Skills Rating System (SSRS, Gresham \& Elliott, 1990) validated by Fortin, Royer, Marcotte, Potvin, and Joly (2001). This scale consists of seven items scored on a Likert scale from not at all capable (1) to totally capable (7). For instance, one item is "Comment te sens-tu capable de contrôler tes humeurs avec tes pairs" (i.e., "How well can you manage your mood with your peers?"). This item was adapted to the sport context and changed to "How well can you manage your mood with your opponents?" Three items that could not be adapted to the sport context were removed. The remaining items were deemed very similar to those composing the negative affective efficacy subscale of the Regulatory Emotional Self-Efficacy (RESE) scale (Caprara \& Gerbino, 2001) and were thus considered appropriate to measure this construct among French participants. In the current study, a CFA showed that the four-item model was significantly adjusted to the data, that is, $\chi^{2}(2)$ $=7.58 ; N=804 ; \mathrm{CFI}=.99 ; \mathrm{TLI}=.98 ; \mathrm{RMSEA}=.059 ; \mathrm{CI} \mathrm{RMSEA}=.019 / .106$. The scale demonstrated satisfactory internal consistency $(\alpha=.84)$.

Social Self-Efficacy. Social self-efficacy was assessed using a validated French version of the Social Efficacy Scale from Bandura et al. (1996) adapted to the sport context. The original scale measures children's beliefs in their capabilities to form and maintain social relationships, work cooperatively with others, and manage different types of interpersonal conflict. This scale consists of five items scored on a Likert scale from not at all capable (1) to totally capable (7). For instance, one item of the original scale is "How well can you express your opinions when other classmates disagree with you?" This item was adapted to the sport context and changed to "How well can you express your opinions when other teammates disagree with you?" Five items that could not be adapted to the sport context were removed.

We used the same validation process as for the resistive self-regulatory efficacy scale. An initial factorial analysis with 270 participants suggested the elimination of three items; a subsequent factorial analysis with 526 other students revealed that the five-item model was significantly adjusted to the data, $\chi^{2}(5)=6.43 ; N=526$; CFI 
$=.99 ; \mathrm{TLI}=.99 ; \mathrm{RMSEA}=.034 ; \mathrm{CI}$ RMSEA $=.000 / .080$. In the current study, the original five-item model showed some acceptable fit, $\chi^{2}(5)=49.99 ; N=804$; CFI = .98; TLI = .95, but exhibited a poor fit for RMSEA (RMSEA = .106; CI RMSEA $=.080 / 133$ ), according to $\mathrm{Hu}$ and Bentler (1999). A respecified model including a path from Item 4 to Item 5 provided a good fit, $\chi^{2}(4)=6.23 ; N=804 ; \mathrm{CFI}=.99$; $\mathrm{TLI}=.99 ; \mathrm{RMSEA}=.026 ;$ CI RMSEA $=.000 / .064$. The internal consistency of the scale was satisfactory $(\alpha=.92)$.

Prosocial Behavior. Prosocial behavior was assessed using a French-Canadian instrument developed by Parrila, Ma, Fleming, and Rinaldi (2002). This instrument is composed of 10 items: four items (e.g., Helps other children who are sick; Praises the work of less able children) are based on the Prosocial Behavior Questionnaire (PBQ; Weir \& Duveen, 1981). The six other items (e.g., Tries to stop a quarrel or dispute; Will help someone who has been hurt) are based on the Ontario Child Health Study (Offord, Boyle, Fleming, Blum, \& Grant, 1989). These items are relevant for adolescents' use. They are scored on a Likert scale from not at all right for me (1) to totally right for me (7). In the current study, the words "peers," "another child," or "someone" were changed to "partners" to adapt to the teamsports context. Examples of items are "Generally, I try to stop a quarrel between partners" or "Generally, I try to help a partner who's been injured." Two items that could not be adapted to the sport context were not considered. In the current study, a CFA was used to examine the factorial structure of the scale. The results supported the hypothesized eight-item model, $\chi^{2}(20)=98.08 ; N=804 ; \mathrm{CFI}=.95$; TLI $=.93 ;$ RMSEA $=.070 ;$ CI RMSEA $=.056 / .084$. This subscale demonstrated satisfactory internal consistency $(\alpha=.79)$.

Moral Disengagement Moral disengagement was assessed with the Echelle Courte du Désengagement Moral en Sport (ECDMS), which is the French Short Moral Disengagement Scale recently developed and validated by Corrion, Scoffier, Gernigon, Cury, and d'Arripe-Longueville (in press). This scale was developed both on the basis of the French translation of the Moral Disengagement in Sport Scale-Short (MDSS-S) by Boardley and Kavussanu (2008), and on the findings of a qualitative study conducted among French athletes (Corrion et al., 2009b). This qualitative study identified two main groups of moral disengagement mechanisms: (a) the projection of fault onto others (including meaning units related to attribution of blame, displacement of responsibility, and diffusion of responsibility) and (b) the minimization of transgressions and their consequences (including meaning units related to euphemistic labeling and other units related to minimizing, distorting, or ignoring consequences). Moral justification, advantageous comparison, and dehumanization did not emerge as significant perceived moral disengagement mechanisms in French athletes' verbalizations (Corrion et al., 2009b), and thus they were not included in the French validation process of the scale (Corrion et al., in press). Examples of items measuring the projection of fault onto others are "It is unfair to blame players who play only a small part in the unsportspersonlike tactics used by their team"; "It's not my fault if I behave badly-cheating or aggression-because it's my opponent who started it." An example of an item measuring euphemistic labeling within the "minimization of transgressions and their consequences" group of mechanisms is "Bending the rules is a way of evening things up." The five items of the scale were scored on a Likert scale from not at 
all right for me (1) to totally right for me (7). In the current study, CFA provided support for the five-item model, $\chi^{2}(4)=18.47 ; N=804 ;$ CFI $=.99$; TLI $=.97$; RMSEA $=.067$; CI RMSEA $=.038 / .099$, and the measure achieved adequate reliability $(\alpha=.81)$.

Judgment of the Acceptability and Likelihood of Cheating. A series of scenarios were developed based in part on the Judgments About Moral Behavior in Youth Sport Questionnaire (JAMBYSQ; Stephens, Bredemeier, \& Shields, 1997) and the measures used in previous studies (Murdock, Miller, \& Kohlhardt, 2004; Kavussanu \& Roberts, 2001; Stuntz \& Weiss, 2003). Our measure comprised five scenarios describing typical situations in team sports in which players might be tempted to cheat. The instrument aimed at measuring the extent to which adolescents would be able to justify cheating (i.e., judgment of cheating acceptability; Murdock et al., 2004) in a sport context. All protagonists were male to reduce potential gender differences in perceived acceptability of unsportpersonlike play (e.g., Crick, 1997; Stuntz \& Weiss, 2003). A typical scenario is as follows:

Christopher is playing in an important basketball match. There is little time left to play, and an opponent launches a counter-attack at a moment when Christopher's team is ahead by only a point. The only way Christopher can stop his opponent from scoring a point is to break a rule (pull on his opponent's jersey) and leave the fate of the game to a free throw.

After reading each scenario, participants answered a series of questions. First, one question invited the participant to reach a verdict on the acceptability of cheating in a team sport context: "Do you think it's OK to behave like X?" Then they rated how likely they would be to act in the same way if put into the protagonist's situation (likelihood to engage in sport cheating). Participants responded on scales from 1 (strongly disagree) to 5 (strongly agree).

A pilot study $(N=100)$ was conducted to determine whether the seven original scenarios were appropriate for French youth in this age group. The results of the first CFA suggested the removal of two scenarios and indicated that modification was well served: $\chi^{2}(5)=13.65 ; N=100 ; \mathrm{CFI}=.97 ; \mathrm{TLI}=.96 ; \mathrm{RMSEA}=.053$; CI $\mathrm{RMSEA}=.019 / .081$. In the current study, a CFA was used to examine the factorial structure of the instrument. The results supported the hypothesized five-scenario model for both cheating acceptability, $\chi^{2}(5)=13.84 ; N=804 ; \mathrm{CFI}=.99$; $\mathrm{TLI}=.98$; RMSEA $=.047$; CI RMSEA $=.018 / .077$, and likelihood of sport cheating, $\chi^{2}(5)$ $=16.44 ; N=804 ; \mathrm{CFI}=.99 ; \mathrm{TLI}=.98 ; \mathrm{RMSEA}=.053 ; \mathrm{CI}$ RMSEA $=.026 / .083$. The scales produced good reliability coefficients $(\alpha=.82$ and $\alpha=.81$, respectively, for acceptability and likelihood of cheating).

\section{Procedure}

The research aims and methods were fully explained to the school directors and teachers, who gave permission to recruit participants from among their students. Information about the study and consent forms was then distributed to the students during class. Only those adolescents who returned a signed parental consent form (those under age 18) and who themselves agreed to participate were enrolled. The participants completed the measures during class approximately one to two 
weeks after the distribution of consent forms. The pilot study suggested that between 25 and 30 min were required to complete the survey in small groups of five participants.

During data collection, participants were told that the research program was an investigation into how youth respect the rules and their opponents in sport. To control for social desirability, participants were reminded to report their own personal thoughts and feelings; they were also told there were no right or wrong answers. To encourage honest answers, students were not asked to put their name on the questionnaires, but only their birth date and the name of their school. This coding system allowed us to match the data from the different collection times. Questionnaire completion was carried out under standardized conditions (i.e., small groups of five, paper, pencil, and prohibition to communicate) at three different times and never exceeded $10 \mathrm{~min}$. The first week, participants completed the selfefficacy measures. The second week, they completed the moral disengagement and the prosocial behavior measures. The third week, participants completed the cheating acceptability and likelihood of cheating measures.

\section{Data Analyses}

The construct validity of the model was examined through CFA. Then the posited causal structural model of relations was tested with the EQS program (Bentler, 1995). We analyzed the structural model by using the multiple-groups model approach, which estimated the same pattern of relationships among variables simultaneously in the two samples of males and females. In this approach, equivalence among samples is evaluated by constraints that impose identical estimates for the model parameters (Byrne, 1994, 2006). In the current study, the equality constraints were imposed on path coefficients across the gender groups by using the Lagrange multipliers (LM) test (Bentler, 1995). The direct, indirect (i.e., comprising all the indirect paths from one variable to another), and total effects (i.e., comprising the direct path and all indirect paths), for the structural model have been calculated for both genders (Bollen, 1987). Mediations were tested according to MacKinnon and colleagues' recommendations (MacKinnon \& Fairchild, 2009; MacKinnon, Lockwood, Hoffman, West, \& Sheets, 2002).

\section{Results}

\section{Descriptive Statistics and Preliminary Analyses}

Table 1 presents the means and standard deviations for the various sociocognitive factors and the matrix of correlations between them and the beliefs about cheating. Overall, participants scored moderate to high on negative affective self-regulatory efficacy, resistive self-regulatory efficacy, social efficacy, and prosocial behavior. Moreover, they scored low on moral disengagement, cheating acceptability, and likelihood of cheating. In other words, their responses indicated that they were able to regulate their negative affects, resist peer pressure, and maintain good relationships. They also perceived their behavior as prosocial, they did not disengage morally or judge cheating as acceptable, and they were not likely to cheat. 


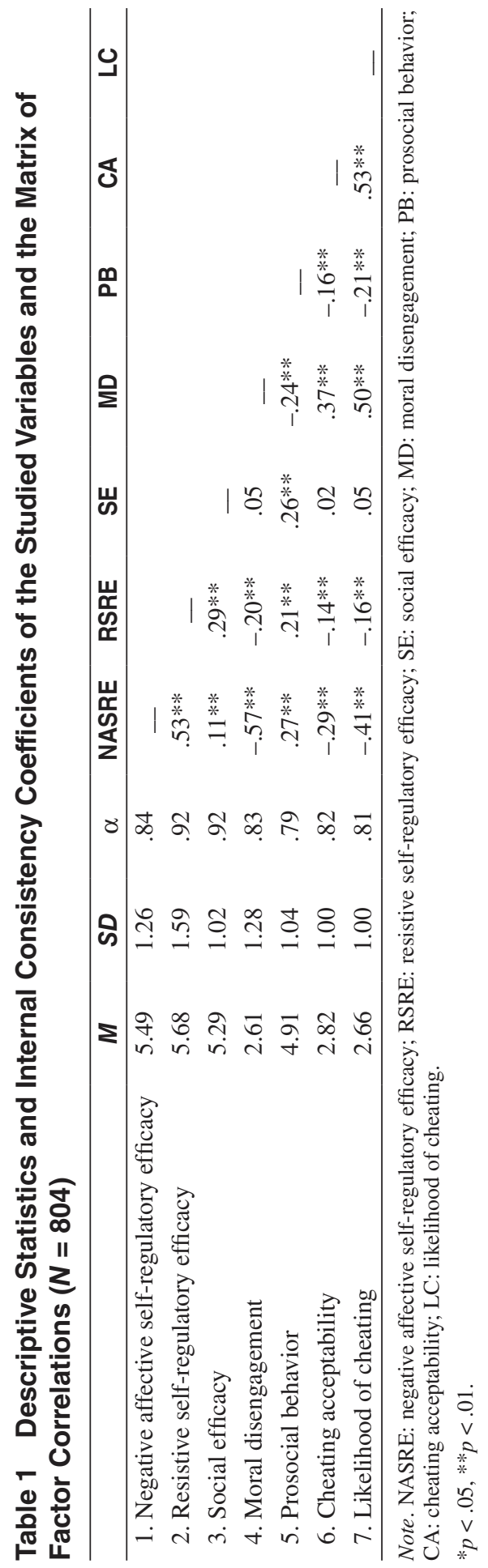


Significant factor correlations ranged in magnitude from low to high and were in the theoretically expected directions. Negative affective self-regulatory efficacy was significantly related to all the other variables. It was positively related to resistive self-regulatory efficacy, social self-efficacy, and prosocial behavior, and negatively related with moral disengagement, cheating acceptability, and likelihood of cheating. Resistive efficacy was also positively associated with social efficacy and prosocial behavior, and negatively related to moral disengagement, judgment of cheating acceptability and likelihood of cheating. Social efficacy was positively associated only with prosocial behavior. Prosocial behavior was negatively related to judgment of cheating acceptability and to likelihood of cheating. Last, moral disengagement was negatively associated with prosocial behavior and positively with cheating acceptability and likelihood of cheating, which was positively related to cheating acceptability.

\section{Testing the Measurement Model}

The measurement model consisted of all items $(N=38)$ measuring negative affective self-regulatory efficacy, resistive self-regulatory efficacy, social self-efficacy, moral disengagement, prosocial behavior, judgment of cheating acceptability, and likelihood of cheating. Bootstrap resampling was performed since the data presented significant multivariate non-normality (normalized skewness and kurtosis: 443.19 and 114.24). This model yielded acceptable fit indexes, $\chi^{2}(639)=1621.71 ; N=$ 804; CFI $=.94 ; \mathrm{TLI}=.93 ; \mathrm{RMSEA}=.044 ; \mathrm{CI}$ RMSEA $=.041 / .046$.

\section{Testing the Hypothesized Model}

The next step involved testing the hypothetical model presented in Figure 1 through structural equation modeling analysis. This model had unacceptable fit, $\chi^{2}(650)=$ 3249.16; NNFI $=.82$; CFI $=.83$; RMSEA $=.070$; CI RMSEA $=.066 / .071$. Thus, the model was respecified based on the Lagrange multiplier (LM) test for adding parameters. Specifically, and in agreement with previous studies reporting high correlations between the legitimacy of and the intention to use unsportspersonlike play (Kavussanu \& Spray, 2006; Stuntz \& Weiss, 2003), four covariances were added between the errors of four items measuring judgment of cheating acceptability and four items measuring likelihood of cheating. The respecified model had a good fit to the data, $\chi^{2}(646)=1363.75 ; \mathrm{NNFI}=.93 ; \mathrm{CFI}=.94 ; \mathrm{RMSEA}=.037$; CI RMSEA $=.035 / .040$.

Next, because of the hypothesized gender differences, we tested the model separately for males and females. The fit indices were satisfactory (see Table 2). Figure 2 shows the results of this analysis. The figure includes all the path coefficients that were significant beyond the .05 level. The total, direct, and indirect effects for the structural model are provided in Table 3 . The results mainly corroborated the posited model and indicated the critical role of negative affective self-regulatory efficacy. The distribution of products test (MacKinnon et al., 2002) showed that all mediations were significant. As hypothesized, negative affective self-regulatory efficacy positively influenced resistive self-regulatory efficacy in males and females, which in turn positively influenced social efficacy; resistive efficacy was a significant mediator of this relationship $\left(\mathrm{P}_{\text {males }}=25.07, p<.001 ; \mathrm{P}_{\text {females }}=15.66, p<.001\right)$. In addition, social efficacy mediated the positive effect of resistive self-regulatory 
efficacy on prosocial behavior in both groups $\left(\mathrm{P}_{\text {males }}=20.32, p<.001 ; \mathrm{P}_{\text {females }}=\right.$ $20.89, p<.001)$. Therefore, resistive self-regulatory efficacy and social efficacy were significant mediators of the positive effect of affective efficacy on prosocial behavior in both groups. Moral disengagement appeared as a significant mediator of the effects of negative affective self-regulatory efficacy on the acceptability of cheating $\left(\mathrm{P}_{\text {males }}=-30.72, p<.001 ; \mathrm{P}_{\text {females }}=-33.83, p<.001\right)$, on the likelihood of cheating $\left(\mathrm{P}_{\text {males }}=-30.52, p<.001 ; \mathrm{P}_{\text {females }}=-28.25, p<.001\right)$, and on prosocial behavior $\left(\mathrm{P}_{\text {males }}=23.33, p<.001 ; \mathrm{P}_{\text {females }}=35.29, p<.001\right)$.

Negative affective self-regulatory efficacy was a direct predictor of the acceptability and likelihood of cheating, in females but not in males. The mediating role of social efficacy in the effect of resistive self-regulatory efficacy on moral disengagement was only evident in males $\left(\mathrm{P}_{\text {males }}=10.80, p<.001\right)$. Similarly, the mediating role of moral disengagement in the effect of social efficacy on prosocial behavior only appeared in males $\left(\mathrm{P}_{\text {males }}=-11.93, p<.001\right)$. Contrary to our hypothetical model, negative affective self-regulatory efficacy did not significantly predict social efficacy, and resistive self-regulatory efficacy was not a direct predictor of cheating variables. Last, social efficacy positively influenced moral disengagement in males, whereas a negative relationship had been hypothesized.

\section{Testing Model Invariance}

Invariance of the model across gender was examined using multigroups structural equation modeling. Based on the recommendations of Byrne (2006) for testing the equivalence of causal models, we tested a series of models with sequentially enforced invariance constraints on model parameters across groups (for a similar approach, see Boardley \& Kavussanu, 2009a). Constrained models were examined in two ways. First, we tested for a significant difference in fit between models, by calculating $\triangle \mathrm{CFI}$, which indicates the magnitude of change in the CFI from one model to another; a magnitude of change that is less than -0.01 indicates no significant difference between two models (Cheung \& Rensvold, 2002). Second, we examined the invariance of individual constraints, by inspecting the LM test results. Constraints were considered variant if they resulted in an increase in $\chi^{2}$ of $\geq 5.0 / d f$. The multisample analyses were conducted in five steps and results are presented in Table 2.

Table 2 Summary of Fit Indices for Multigroup Analyses

\begin{tabular}{lcccccc}
\hline Model & $\boldsymbol{d} \boldsymbol{f}$ & $\chi^{2}$ & NNFI & CFI & RMSEA & CI RMSEA \\
\hline Baseline females & 646 & 1058.83 & 0.926 & 0.932 & 0.039 & $0.035 / 0.043$ \\
Baseline males & 646 & 996.09 & 0.925 & 0.931 & 0.038 & $0.033 / 0.043$ \\
Configural invariance & 1292 & 2056.15 & 0.926 & 0.932 & 0.027 & $0.025 / 0.029$ \\
Metric invariance & 1327 & 2134.43 & 0.924 & 0.928 & 0.028 & $0.025 / 0.030$ \\
ECVC & 1323 & 2091.78 & 0.927 & 0.931 & 0.027 & $0.025 / 0.029$ \\
Structural equivalence & 1338 & 2118.94 & 0.927 & 0.930 & 0.027 & $0.025 / 0.029$ \\
\hline
\end{tabular}

Note $\chi^{2}=$ Satorra-Bentler scaled chi-square; NNFI = Bentler-Bonett non-normed fit index; CFI = comparative fit index; RMSEA = root mean square error of approximation; CI RMSEA $=90 \%$ confidence interval of RMSEA; $\mathrm{ECVC}=$ equivalence of construct variance and covariance. 


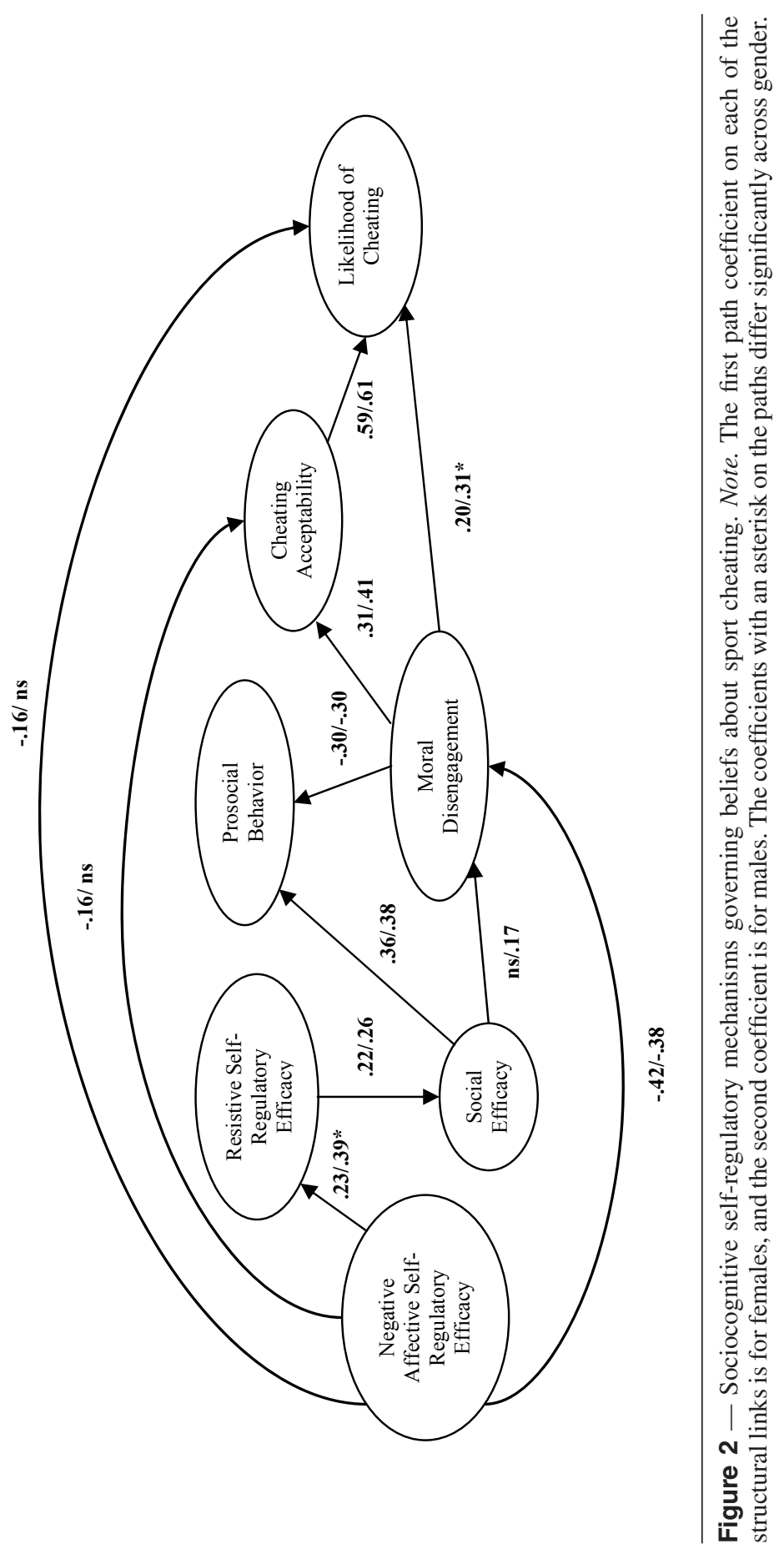




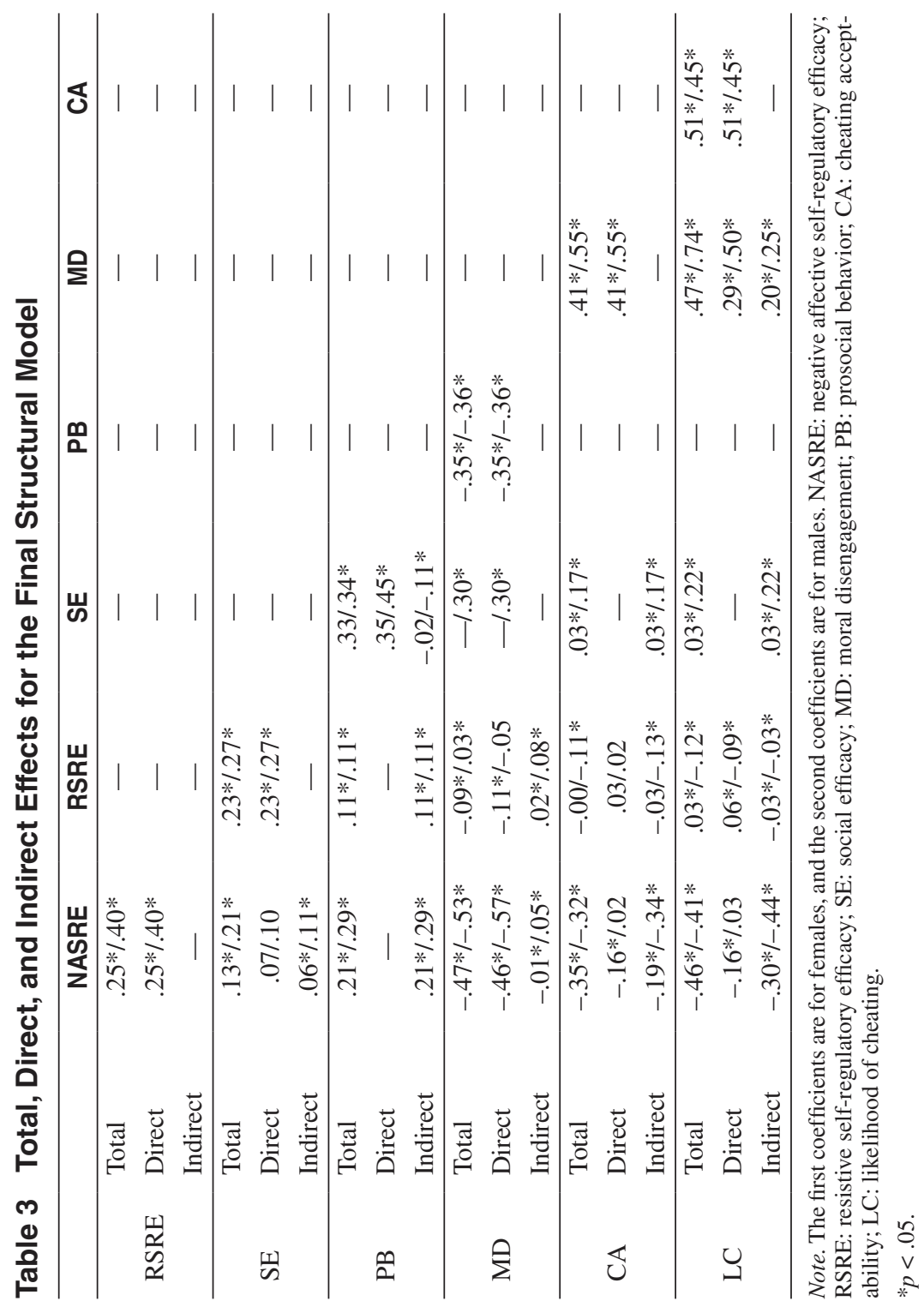


After having tested the aforementioned baseline model separately for females and males, we tested for configural invariance, which exists when all items are indicators of the same factors in all groups. To this end, the model was tested for invariance across the two groups simultaneously without placing any constraints. This model had a good fit, demonstrating configural invariance (see Table 2). The fit indices obtained for the configural invariance model were compared with the more-constrained models tested later (see Byrne, 2006). Next, metric invariance was tested to determine whether factor loadings were equivalent across groups. We did this by constraining all factor loadings to be equal across groups and testing metric invariance (a) at the construct level by inspecting the reduction in overall model fit, and (b) at the item level by examining the results of the LM test. Construct-level metric invariance was demonstrated by a $\Delta \mathrm{CFI}$ of -0.004 between the configural and construct-level metric invariance models. However, the LM test results suggested that the factor loadings for one resistive efficacy item $\left(\Delta \chi^{2}=13.81, p<.001\right)$, one social efficacy item $\left(\Delta \chi^{2}=6.53, p<.01\right)$, and one prosocial behavior item $\left(\Delta \chi^{2}=5.27, p<.05\right)$ were noninvariant across the two genders, along with two covariances between the errors of two judgment of cheating acceptability and likelihood of cheating items $\left(\Delta \chi^{2}=11.04, p<.001\right.$ and $\left.\Delta \chi^{2}=8.38, p<.01\right)$. These results indicated partial metric invariance in the model (see Byrne, Shavelson, \& Muthén, 1989). As such, all previously imposed equality constraints were retained except those found to be noninvariant in the next step of invariance testing.

Fourth, we tested for the equivalence of construct variance and covariance across females and males. This model determines whether the variances and covariances of the observed and latent variables are equivalent across groups. The $\Delta \mathrm{CFI}$ of this model compared with the configural invariance model was -0.001 , demonstrating the equivalence of construct variance and covariance across females and males. The LM test indicated that the variance of negative affective self-regulatory efficacy was invariant across groups. Last, we tested for structural equivalence by constraining causal paths to be equal across groups. The $\Delta C F I$ compared with the configural invariance model was -0.002 , indicating structural equivalence. However, the LM test indicated that the path between moral disengagement and likelihood of cheating $\left(\Delta \chi^{2}=9.22, p<.01\right)$, and the path between affective efficacy and resistive efficacy $\left(\Delta \chi^{2}=5.54, p<.05\right)$ were noninvariant. Specifically, these path coefficients were higher for males than for females. Overall, these analyses demonstrated that the measurement and structural models are largely invariant across females and males.

Finally, examination of the invariance of latent factor means (Byrne, 2006) indicated that females had significantly higher scores on prosocial behavior $(\Delta$ latent factor mean $=0.43, S E=.07, t=6.09, p<.001)$ than males. In contrast, males had significantly higher scores on moral disengagement ( $\Delta$ latent factor mean $=-0.37, S E=.08, t=-4.45, p<.001)$, cheating acceptability $(\Delta$ latent factor mean $=-0.32, S E=.06, t=-5.47, p<.001)$ and likelihood of cheating $(\Delta$ latent factor mean $=-0.32, S E=.06, t=-5.10, p<.001)$ than females. No gender differences were found in affective efficacy, resistive efficacy, and social efficacy $(\Delta$ latent factor means $<0.19, n s)$. 


\section{Alternative Models}

A number of alternative causal models were also tested. In one model, the acceptability and likelihood of cheating were assigned causal primacy influencing affective efficacy directly and through their impact on moral disengagement, prosocial behavior, and other self-efficacy beliefs. Another model conferred causal primacy on social-efficacy and resistive efficacy which contributed to distal cheating directly and through their influence on affective self-regulatory efficacy, prosocial behavior, and moral disengagement. In each case, the alternative causal models provided a poorer fit to the empirical data than did the posited structural model. All the chisquare tests were significant, and these alternative models fared less well on the other indexes of goodness of fit.

\section{Discussion}

The findings of this research provide a good empirical fit to the structural model specifying how perceived affective self-regulatory efficacy operates in concert with resistive and social efficacy to regulate prosocial behavior and beliefs about cheating in sport. Examination of the latent mean differences indicated that male and female participants differed in the level of some of the studied variables. That the males obtained higher scores than the females in moral disengagement and in beliefs about cheating is in line with earlier results from the literature in both social psychology (e.g., Bandura et al., 2001, 2003) and sport psychology (e.g., Boardley \& Kavussanu, 2007; Gardner \& Janelle, 2002; Miller et al., 2005) literatures. Moreover, consistent with our hypotheses based on previous studies (Bandura et al., 2001, 2003; Caprara \& Steca, 2005), the female adolescents expressed higher scores in prosocial behavior. However, no gender differences were found in selfefficacy variables, while previous studies have reported higher negative affective efficacy in males (Bandura et al., 2003; Caprara \& Steca, 2005), and higher resistive self-regulatory efficacy in females (e.g., Bandura et al., 2001). These discrepant findings might be due to the different contexts under study (daily life vs. sport) and cultural differences (French vs. American adolescents).

Some of the predicted causal structures were the same for both groups, while some relationships differed by gender. In accordance with our prediction based on Bandura et al. (2003), negative affective self-regulatory efficacy negatively influenced the acceptability and likelihood of cheating, through the mediating role of moral disengagement, in males and females. Furthermore, negative affective efficacy positively influenced prosocial behavior through resistive self-regulatory efficacy and social-efficacy, thus extending the findings of Bandura et al. (2001). Negative affective efficacy directly affected the acceptability and likelihood of cheating in females only; for males, this effect was indirect. Contrary to our hypotheses, negative affective efficacy did not directly influence social efficacy but did so indirectly through resistive efficacy. Social efficacy played a mediational role between resistive efficacy and prosocial behavior, providing support to earlier studies (Bandura et al., 2001; Caprara \& Steca, 2005). Furthermore the expected direct effect of resistive self-regulatory efficacy on moral disengagement and cheating variables (Bandura et al., 2001) was not observed; however, the observed indirect effects through social efficacy and moral disengagement suggest that the paths of influence through 
which different facets of self-efficacy govern variables related to transgressiveness might depend on their context of emergence (daily life vs. sport). It should also be noted, however, that the variables under study and the instruments used were not exactly the same in the different studies. For example, transgressive behavior was considered by Bandura and colleagues, whereas beliefs about cheating were examined in the current study.

Our posited model also aimed at extending the models of Bandura et al. (2001, 2003) by examining new relationships between the selected variables. We found that moral disengagement significantly mediated the effects of (a) negative affective efficacy on the acceptability and likelihood of sport cheating, and (b) negative affective efficacy on prosocial behavior, in males and females. Both of these effects occurred through social and resistive self-efficacy in males. These findings partly extend previous results in the psychosocial literature in which empathic self-efficacy was found to mediate the relationships between affective self-regulatory efficacy and prosocial behavior (Bandura et al., 2003), and between positive affective efficacy and prosocial behavior (Gano-Overway et al., 2009). They also provide additional support to the mediational role of moral engagement between self-perceptions such as perceived character-building competency and prosocial or antisocial behaviors, which has recently been highlighted in the sport psychology literature (Boardley \& Kavussanu, 2009a).

Although the causal structures were essentially the same for both groups, a few paths differed by gender. First, an unexpected positive relationship between social efficacy and moral disengagement was observed in males. Although the constructs are different, this finding might accord with the results of Stuntz and Weiss (2003) who observed that boys who gave high ratings on friendship and group acceptance goal orientations intended to engage in unsportspersonlike play. This finding would also lend support to Houghton and Carroll's (1996) proposal that male adolescents' classroom reputation and self-perceptions are related to feedback from peers for being disruptive. Another explanation for this result would be the potential for learning to use moral disengagement during social interactions. Increased social efficacy may lead to a greater number of social interactions during which moral disengagement can be learned from peers. Since the males of the current study used moral disengagement more frequently than females, this may explain why this relationship was seen in males but not in females. The higher scores of males in moral disengagement and in beliefs about cheating may also explain why moral disengagement influenced the likelihood of cheating more strongly in males than in females.

Next, the link between negative affective efficacy and resistive self-regulatory efficacy was also stronger for males, although no gender differences were found in the self-efficacy variables of this study. Our findings do not provide support to Bandura et al. (2001, 2003) who did not report similar gender differences. This discrepancy might be due to the specific characteristics of the physical activity contexts, and these findings need to be confirmed in further research. Finally, the finding that negative affective efficacy was a direct predictor of cheating variables in females, while this effect was indirect in males, might suggest different educational strategies according to gender.

Along with recent research (Bandura et al., 2003; Caprara \& Steca, 2005; Gano-Overway et al., 2009), this study showed that affective self-regulatory efficacy 
is an important facet of self-efficacy that needs to be taken into account to better understand adolescents' prosocial behavior and beliefs about antisocial conduct. Our findings confirmed the results of previous work in the academic domain, but they did not corroborate the finding by Gano-Overway et al. (2009) that negative affective self-regulatory efficacy does not predict antisocial behavior. Although antisocial behavior is related to the concepts of moral disengagement, cheating acceptability and the likelihood of cheating, it nevertheless differs from these concepts. This could explain why the current study did not confirm the results of Gano-Overway et al. (2009). Our results provided evidence for the significant mediational role of moral disengagement in the relationships between different facets of self-efficacy and prosocial behavior or beliefs about cheating. They also suggest interesting new directions for moral development studies in physical activity settings based on Bandura's (1986) social learning perspective (e.g., Giebink \& McKenzie, 1985; Mugno \& Feltz, 1985). They enrich Lucidi et al.'s (2004, 2008) findings about the sociocognitive mechanisms regulating the use of doping substances, as well as the preliminary results on the self-regulatory mechanisms governing transgressive behaviors in sport (d'Arripe-Longueville et al., 2005; Boardley \& Kavussanu, 2009a, 2009b). Not least, our study adds to the explanatory and predictive generality of sociocognitive theory (Bandura et al., 2001, 2003) and suggests that negative affective efficacy, resistive self-regulatory efficacy and social-efficacy may be important constructs to consider in future moral development research in physical activity contexts.

It is important to note that our results were obtained with complete temporal separation of the independent, intermediary, and outcome variables. This degree of control is uncommon and lends confidence to the robustness of the observed relations. Nevertheless, as with all correlational designs, there is the omitted variable problem. Even if we can rule out reverse causality, there is always the possibility that variables not assessed accounted for some or all of the relationships between the variables that were assessed. Thus, it would be interesting to replicate these findings using an experimental design. Our findings suggest several other lines of research in sport psychology. Specific affects like irritability or ruminative affectivity, which were included in Bandura et al.'s (2001) original model, could be considered. As this study focused only on perceived efficacy to manage negative affect, future work might examine perceived efficacy to express positive affect. In line with an achievement goal approach to studying moral functioning in sport (e.g., Kavussanu \& Roberts, 2001; Boardley \& Kavussanu, 2009a), it might be particularly interesting to examine how achievement goals and the perceived motivational climate affect self-regulatory efficacy and consequently moral disengagement and sport cheating behaviors. Last, in line with earlier sociomoral education programs (e.g., Gibbons, Ebbeck, \& Weiss, 1995; Hellison, Martineck, \& Cutforth, 1996), future moral development research could examine the impact of intervention programs that encourage the learning of self-regulatory skills on youth moral functioning in sport and physical activity contexts. Other research might test different educational strategies according to gender.

To conclude, the current study emphasizes the role of affective and resistive self-regulatory efficacy to improve moral functioning in sport and physical activity contexts via the mediating role of moral self-sanctions. Future studies that simultaneously target personal and contextual variables and intervention research promoting 
self-regulatory efficacy could allow practitioners to help youth acquire effective skills to manage the stressors related to moral dilemmas in sport and life contexts.

\section{Acknowledgments}

This study was supported by a grant of the French Ministry of Health and Sport. The authors are grateful to the participants and Catherine Carmeni for help in the translation. They also sincerely thank two anonymous reviewers for their helpful comments on earlier drafts.

\section{References}

Ajzen, I. (1991). The theory of planned behavior. Organizational Behavior and Human Decision Processes, 50, 179-211.

Arbuckle, J.L. (2008). AMOS 17 User's Guide. Chicago: SPSS Inc.

d'Arripe-Longueville, F., Weiss, M.R., Pantaleon, N., \& Raimbault, N. (2005, July). Selfregulatory mechanisms governing beliefs about unsportsmanlike play in adolescent basketball players. Presentation given at the International Conference for the French Society for the Psychology of Sport, Reims, France.

Bandura, A. (1986). Social foundations of thought and action: A social cognitive theory. Englewood Cliffs, NJ: Prentice Hall.

Bandura, A. (1991). Social cognitive theory of moral thought and action. In W.M. Kurtines \& J.L. Gewirtz (Eds.), Handbook of moral behavior and development: Theory, research and applications (Vol. 1, pp. 45-103). Hillsdale, NJ: Lawrence Erlbaum Associates, Inc.

Bandura, A. (1999). Moral disengagement in the perpetration of inhumanities. Personality and Social Psychology Review, 3, 193-209.

Bandura, A., Barbaranelli, C., Caprara, G.V., \& Pastorelli, C. (1996). Multifaceted impact of self-efficacy beliefs on academic functioning. Child Development, 67, 1206-1222 .

Bandura, A., Caprara, G.V., Barbaranelli, C., Gerbino, M., \& Pastorelli, C. (2003). Role of affective self-regulatory efficacy in diverse spheres of psychosocial functioning. Child Development, 74, 769-782.

Bandura, A., Caprara, G.V., Barbaranelli, C., Pastorelli, C., \& Regalia, C. (2001). Sociocognitive self-regulatory mechanisms governing transgressive behaviors. Journal of Personality and Social Psychology, 80, 125-135.

Bandura, A., Pastorelli, C., Barbaranelli, C., \& Caprara, G.V. (1999). Self-efficacy pathways to childhood depression. Journal of Personality and Social Psychology, 76, 258-269.

Bentler, P.M. (1995). EQS structural equations program manual. Encino, CA: Multivariate Software.

Boardley, I.D., \& Kavussanu, M. (2007). Development and validation of the Moral Disengagement in Sport Scale. Journal of Sport \& Exercise Psychology, 29, 608-628.

Boardley, I.D., \& Kavussanu, M. (2008). The Moral Disengagement in Sport Scale - short. Journal of Sports Sciences, 26, 1507-1517.

Boardley, I.D., \& Kavussanu, M. (2009a). The influence of social variables and moral disengagement on prosocial and antisocial behaviors in field hockey and netball. Journal of Sports Sciences, 27, 843-854.

Boardley, I.D., \& Kavussanu, M. (2009b, June). Do efficacy beliefs and social goals predict prosocial behavior in sport? Paper presented at the 12th World Congress of Sport Psychology. Marrakech, Morocco.

Bredemeier, B.J. (1985). Moral reasoning and the perceived legitimacy of intentionally injurious sport acts. Journal of Sport Psychology, 7, 110-124.

Bredemeier, B.J., \& Shields, D.L. (1986). Moral growth among athletes and non-athletes: A comparative analysis. The Journal of Genetic Psychology, 147, 7-18. 
Bollen, K.A. (1987). Total, direct, and indirect effects in structural equation models. Sociological Methodology, 17, 37-69.

Byrne, B. (1994). Testing the factorial validity, replication, and invariance of a measuring instrument: A paradigmatic application based on the Maslach Burnout Inventory. Multivariate Behavioral Research, 29, 289-311.

Byrne, B. (2006). Structural equation modeling with EQS: Basic concepts, applications, and programming (2nd ed.). Mahwah, NJ: Lawrence Erlbaum Associates.

Byrne, B., Shavelson, R.J., \& Muthén, B. (1989). Testing for the equivalence of factor covariance and mean structures: The issue of partial measurement invariance. Psychological Bulletin, 105, 456-466.

Caprara, G.V., \& Gerbino, M. (2001). Autoeficacia Emotiva Percepita: la capacita di regolare l'affettivita negativa e di esprimere quella positiva. In G.V. Caprara (Ed.), La valutatione dell' autoefficacia (pp. 35-50). Trento: Edizioni Erickson. [Self-efficacy assessment].

Caprara, G.V., Regalia, C., \& Bandura, A. (2002). Longitudinal impact of perceived selfregulatory efficacy on violent conduct. European Psychologist, 7, 63-69.

Caprara, G.V., Scabini, E., Barbaranelli, C., Pastorelli, C., Regalia, C., \& Bandura, A. (1998). Impact of adolescents' perceived self-regulatory efficacy on familial communication and antisocial conduct. European Psychologist, 3, 125-132.

Caprara, G.V., \& Steca, P. (2005). Self-efficacy beliefs as determinants of prosocial behavior conducive to life satisfaction across ages. Journal of Social and Clinical Psychology, 24, 191-217.

Cheung, G.W., \& Rensvold, R.B. (2002). Evaluating goodness of fit indexes for testing measurement invariance. Structural Equation Modeling, 9, 233-255.

Corrion, K., Gernigon, C., Garbarino, J.M., Cury, F., \& d'Arripe-Longueville, F. (2009a, July). Développement et validation française de l'échelle de résistance à la pression sociale en sport (ERPSS). [Development and French validation of the resistive self-regulatory efficacy scale in sport]. Paper presented at the Congrès International de Psychologie $d u$ Sport, Paris, France.

Corrion, K., Long, T., Smith A. L., \& d'Arripe-Longueville, F. (2009b). "It's not my fault; It's not serious": Athlete accounts of moral disengagement in competitive sport. The Sport Psychologist, 23, 388-404.

Corrion, K., Scoffier, S., Gernigon, C., Cury, F., \& d'Arripe-Longueville, F. (in press). Développement et validation d'une Echelle Courte de Désengagement Moral en Sport (ECDMS) [Development and factorial validity of a Short Moral Disengagement in Sport Scale]. L'Encéphale.

Crick, N.R. (1997). Engagement in gender normative versus nonnormative forms of unsportsmanlike play: Links to social-psychological adjustment. Developmental Psychology, 33, 610-617.

Eisenberg, N., \& Fabes, R.A. (1998). Prosocial development. In N. Eisenberg (Ed.), Handbook of child psychology. Vol 3: Social, emotional, and personality development (pp. 701-778). New York: Wiley.

Fortin, L., Royer, E., Marcotte, D., Potvin, P., \& Joly, J. (2001). Epreuves de validité d'une mesure d'habiletés sociales auprès d'adolescents québécois à l'école secondaire [Validation of a social skill measure in Quebec secondary school adolescents]. Psychologie et Psychométrie, 22, 23-43.

Gano-Overway, L.A., Newton, M., Magyar, T.M., Fry, M.D., Kim, M.S., \& Guivernau, M.R. (2009). Influence of caring youth sport contexts on efficacy-related beliefs and social behaviors. Developmental Psychology, 45, 329-340.

Gardner, R.E., \& Janelle, C.M. (2002). Legitimacy judgments of perceived aggression and assertion by contact and non-contact sport participants. International Journal of Sport Psychology, 33, 290-306. 
Gibbons, S.L., Ebbeck, V., \& Weiss, M.R. (1995). Fair play for kids: Effects on the moral development of children in physical education. Research Quarterly for Exercise and Sport, 66, 247-255.

Giebink, M.P., \& McKenzie, T.C. (1985). Teaching sportsmanship in physical education and recreation: An analysis of intervention and generalization effects. Journal of Teaching in Physical Education, 4, 167-177.

Gresham, F.M., \& Elliott, S.N. (1990). Social Skills Rating System (SSRS). Circle Pines, MN: American Guidance Service.

Gross, J.J., \& Munoz, R.F. (1995). Emotion regulation and mental health. Clinical Psychology: Science and Practice, 2, 151-164.

Hellison, D., Martineck, T., \& Cutforth, N. (1996). Beyond violence prevention in inner city physical activity programs. Peace and Conflict, 2, 321-338.

Houghton, S., \& Carroll, A.M. (1996). Enhancing reputations: High school adolescent males' effective use of teacher behavior intervention strategies. Scientia Paedagogica Experimentalis, 33, 227-244.

Hu, L., \& Bentler, P.M. (1999). Cutoff criteria for fit indexes in covariance structure analysis: Conventional criteria versus new alternatives. Structural Equation Modeling, 6, 1-55.

Kavussanu, M. (2006). Motivational predictors of prosocial and antisocial behavior in football. Journal of Sports Sciences, 24, 575-588.

Kavussanu, M., \& Roberts, G.C. (2001). Moral functioning in sport: An achievement goal perspective. Journal of Sport \& Exercise Psychology, 23, 37-54.

Kavussanu, M., Seal, A.R., \& Phillips, D.R. (2006). Observed prosocial and antisocial behaviors in male soccer teams: Age differences across adolescence and the role of motivational variables. Journal of Applied Sport Psychology, 18, 326-344.

Kavussanu, M., \& Spray, C.M. (2006). Contextual influences on moral functioning of male youth footballers. The Sport Psychologist, 20, 1-23.

Larsen, R.J. (2000). Toward a science of mood regulation. Psychological Inquiry, 11, 129-141.

Lee, M.J., Whitehead, J., Ntoumanis, N., \& Hatzigeorgiadis, A. (2008). Relationships among values, achievement orientations, and attitudes in youth sport. Journal of Sport \& Exercise Psychology, 30, 588-610.

Leffert, N., \& Petersen, A. (1995). Patterns of development during adolescence. In M. Rutter \& D. Smith (Eds.), Psychosocial disorders in young people (pp. 67-103). Chichester, UK: Wiley.

Long, T., Pantaléon, N., Bruant, G., \& d'Arripe-Longueville, F. (2006). A qualitative study of moral reasoning of young elite athletes. The Sport Psychologist, 20, 330-347.

Lucidi, F., Grano, C., Leone, L., Lombardo, C., \& Pesce, C. (2004). Determinants of the intention to use doping substances: An empirical contribution in a sample of Italian adolescents. International Journal of Sport Psychology, 35, 133-148.

Lucidi, F., Zelli, A., Mallia, L., Grano, C., Russo, P.M., \& Violani, C. (2008). The socialcognitive mechanisms regulating adolescents' use of doping substances. Journal of Sports Sciences, 26, 447-456.

MacKinnon, D.P., \& Fairchild, A.J. (2009). Current directions in mediation analysis. Current Directions in Psychological Science, 18, 16-20.

MacKinnon, D.P., Lockwood, C.M., Hoffman, J.M., West, S.G., \& Sheets, V. (2002). A comparison of methods to test mediation and other intervening variable effects. Psychological Methods, 7, 83-104.

Miller, B.W., Roberts, G.C., \& Ommundsen, Y. (2005). Effect of perceived motivational climate on moral functioning, team moral atmosphere perceptions, and the legitimacy of intentionally injurious acts among competitive youth football players. Psychology of Sport and Exercise, 6, 461-477. 
Mugno, D.A., \& Feltz, D.L. (1985). The social learning of aggression in youth football in the United States. Canadian Journal of Applied Sport Sciences, 10, 26-35.

Murdock, T.B., Miller, A., \& Kohlhardt, J. (2004). Effects of classroom context variables on high school students' judgments of acceptability and likelihood of cheating. Journal of Educational Psychology, 96, 765-777.

Offord, D.R., Boyle, M.H., Fleming, J.E., Blum, H.M., \& Grant, N.I. (1989). Ontario Child Health Study. Summary of results. Canadian Journal of Psychiatry, 34, 483-491.

Parrila, R.K., Ma, X., Fleming, D., \& Rinaldi, C. (2002). Développement des compétences prosociales. [Development of Prosocial Skills]. Rapport de la Direction Générale de la Recherche Appliquée, Canada. Available in www.rhdcc.gc.ca. 0-662-33444-2, RH63-1/550-12-02E.

Sage, L., Kavussanu, M., \& Duda, J.L. (2006). Goal orientations and moral identity as predictors of prosocial and antisocial functioning in male association football players. Journal of Sports Sciences, 24, 455-466.

Shields, D.L., Bredemeier, B.L., LaVoi, N.M., \& Power, C.F. (2005). The behavior of youth, parents, and coaches: The good, the bad, and the ugly. Journal of Research in Character Education, 3, 43-59.

Stephens, D.E., Bredemeier, B.J.L., \& Shields, D.L.L. (1997). Construction of a measure designed to assess players' descriptions and prescriptions for moral behavior in youth sport soccer. International Journal of Sport Psychology, 28, 370-390.

Stuntz, C.P., \& Weiss, M.R. (2003). Influence of social goal orientations and peers on unsportsmanlike play. Research Quarterly for Exercise and Sport, 74, 421-435.

Vallerand, R.J. (1989). Vers une méthodologie de validation transculturelle de questionnaires psychologiques: Implications pour la recherche en langue française [Toward a methodology for transcultural validation of psychological questionnaires: Implications for research in the French language]. Canadian Psychology, 4, 662-680.

Weinstein, M.D., Smith, M.D., \& Wiesenthal, D.L. (1995). Masculinity and hockey violence. Sex Roles, 33, 831-847.

Weiss, M.R., Smith, A.L., \& Stuntz, C.P. (2008). Moral development in sport and physical activity. In T.S. Horn (Ed.), Advances in sport psychology (3rd ed., pp. 187-210). Champaign, IL: Human Kinetics.

Weir, K., \& Duveen, G. (1981). Further development and validation of the prosocial behavior questionnaire for use by teachers. Journal of Child Psychology and Psychiatry, and Allied Disciplines, 22, 357-374.

Manuscript received: July 17, 2009

Revision accepted: May 15, 2010 